\title{
INTERFACES ENTRE 0 REGIME INTERNACIONAL DE MUDANÇA CLIMÁTICA E A SAÚDE GLOBAL
}

Danielle Hanna Rached

Doutora em Direito Internacional Público pela Universidade de Edimburgo. Pós-doutoranda do Instituto de Relações Internacionais, Universidade de São Paulo. Bolsista da FAPESP (Fundação de Amparo à Pesquisa do Estado de São Paulo), São Paulo, SP, Brasil. Email < daniellerached@googlemail.com > http://dx.doi.org/10.1590/ 0102-6445231-254/98

A mudança climática é um dos maiores desafios do nosso tempo. [...] Diante deste desafio, precisamos trabalhar para colocar a proteção da saúde humana no centro da agenda da mudança climática. (CHAN, 2008)

Saúde global e mudança climática são fenômenos mutuamente implicados. A aproximação entre ambos, do ponto de vista jurídico e institucional, constitui um dos maiores desafios das relações internacionais contemporâneas. Margaret Chan, diretora-geral da Organização Mundial de Saúde (OMS), por exemplo, tem enfatizado o quanto a saúde da população global será diretamente afetada pelas consequências alarmantes da alteração climática. Na epígrafe deste artigo, ela indica que as decisões adotadas no contexto da mudança climática precisariam levar mais em conta as preocupações relacionadas à saúde dos indivíduos. No entanto, em razão da natureza altamente fragmentada do direito internacional, as decisões sobre saúde global e sobre mudança climática são adotadas em fóruns distintos. 
Com o objetivo de identificar interfaces entre os dois campos, o presente texto analisa a evolução do Regime Internacional de Mudança Climática: suas características, obstáculos e principais decisões. A saúde humana somente poderá ser protegida e preservada de forma adequada pela articulação e coordenação das diversas instituições que povoam a governança global. Olhar exclusivamente para as decisões da área da saúde há muito deixou de ser suficiente.

O clima nunca foi totalmente previsível e consistente. A variabilidade climática, ou seja, a oscilação natural e não antropogênica do clima, é um fenômeno conhecido, já bastante documentado e descrito por historiadores e cientistas. Por outro lado, a mudança climática é um capítulo à parte. A associação entre clima e mudança, originando a expressão "mudança climática" surgiu para demonstrar o impacto que a interferência humana, ao longo da era industrial, teve e ainda tem sobre o clima. Acredita-se que seu efeito seja profundo e, 232 em certa medida, irreversível.

A escala da mudança climática é supostamente global, mas, sem dúvida, suas consequências afetarão mais diretamente a vida de indivíduos em algumas regiões que em outras. Aliás, as regiões mais diretamente afetadas não são necessariamente aquelas que mais contribuíram - por ter atividade industrial em menor escala - para o problema: "os pobres e mais vulneráveis serão os mais atingidos” pela alteração climática (World Bank, 2012, Prefácio). Logo, a mudança climática é um quebra-cabeça jurídico e político complicado. Gerenciar esse quebra-cabeça tornou-se uma das questões mais urgentes do direito internacional contemporâneo. No entanto, o direito internacional tardou a se preocupar com a questão da mudança climática. Nas últimas três décadas, porém, políticos e legisladores têm demonstrado maior sensibilidade diante do volume de evidências que a ciência produziu sobre o assunto.

As negociações intergovernamentais sobre mudança climática começaram timidamente nos anos 1990 e têm, 
cada vez mais, ocupado a agenda internacional (Skodvin e Andresen, 2011, pp. 166-67). Após uma série de tentativas para construir uma resposta internacional ao problema, a literatura acadêmica oscila entre o fatalismo e o otimismo qualificado sobre as perspectivas de um regime internacional suficientemente forte e capaz ${ }^{1}$.

O Regime Internacional de Mudança Climática, que é o conjunto de acordos multilaterais destinados a resolver a questão, começa, formalmente, com a adoção, em 1992, da Convenção Quadro sobre a Mudança Climática (Keohane e Victor, 2010, p. 4). A Convenção Quadro não impõe obrigações aos Estados para reduzir suas emissões, mas estabelece um arcabouço jurídico, rico em princípios e processos, necessário à condução das negociações intergovernamentais que ocorreriam mais tarde.

O subsequente Protocolo de Quioto, em 1997, parecia um episódio mais promissor da narrativa jurídico-política da mudança climática. O Protocolo estabeleceu metas obrigatórias e um calendário para que os países desenvolvidos reduzissem as emissões de gases que causam o efeito estufa (gases que aprisionam o calor na atmosfera e, consequentemente, são considerados a principal causa da mudança climática). O Protocolo de Quioto ficou conhecido por ter criado mecanismos de mercado, desenhados para que os países desenvolvidos cumprissem suas metas mais facilmente. Os países em desenvolvimento, por outro lado, não tinham obrigações relacionadas à redução de suas emissões ${ }^{2}$.

1 Bodansky (2012, p. 12) já chegou a afirmar que as negociações climáticas parecem ficar presas em uma "metanegociação sobre o que negociar".

2 Em 1992, o Regime Internacional de Mudança Climática dividiu os estados-membros em dois grupos principais: o primeiro grupo, países do Anexo I, é formado pelos estados-membros da Organização para a Cooperação e Desenvolvimento Econômico (OCDE), além dos países com economias em transição. São os "países desenvolvidos" para a literatura especializada. O segundo grupo, países não incluídos no Anexo I, é formado por todos os outros estados-membros, que são majoritariamente os países em desenvolvimento. Ver site Parties $\mathcal{E}$ Observers: <http://unfccc. int/parties_and_observers/items/2704.php>; acesso em: 3 jul. 2016. 
A abordagem jurídico-institucional iniciada com a Convenção Quadro e ampliada pelo Protocolo de Quioto passou por um processo de grande transformação até chegar ao seu formato atual, o Acordo de Paris, de dezembro de 2015. Por esse acordo, qualquer país passa a responder à ameaça da alteração climática por meio de "contribuições nacionalmente determinadas", ou seja, metas voluntárias de redução das emissões, decididas conforme a capacidade particular de cada Estado.

Os diversos impasses que marcaram as rodadas de negociações do Regime Internacional de Mudança Climática demonstram a complexidade da convergência sobre o tema, pois ela envolve o deslocamento de parte da autoridade dos Estados para regular o meio ambiente para um órgão internacional; afeta o ritmo do desenvolvimento econômico de cada Estado, pois, seja qual for o acordo internacional final sobre o assunto, se tal acordo 234 puder realmente ser alcançado e implementado, ele terá de reformular a estrutura e a lógica do sistema produtivo em favor de uma meta internacional profundamente controversa ${ }^{3}$.

Este artigo traça um panorama introdutório, mas abrangente do Regime Internacional de Mudança Climática. Inicia com o conceito de bem comum global e como ele se aplica ao clima e à saúde. Discute como tal classificação afeta o desenho do Regime Internacional de Mudança Climática, cuja evolução é descrita desde o seu início até as últimas rodadas de negociações. Por fim, são feitas considerações sobre os impactos da mudança climática na saúde.

\footnotetext{
3 De acordo com Bodansky (2012, p. 9; tradução da autora): "A mudança climática afeta praticamente todas as áreas da política doméstica, incluindo industrial, agrícola, energética, transporte e política do uso do solo. Como resultado, o Regime Internacional de Mudança Climática gera maiores sensibilidades domésticas que outros regimes internacionais, que possuem um âmbito mais limitado."
} 


\section{Clima e saúde como bens comuns globais}

O sucesso da mobilização internacional para prevenção e combate da propagação internacional das doenças depende, em grande medida, da atuação dos Estados: se e em que medida eles estão dispostos a cooperar entre si. O episódio da gripe A (H1N1) é um exemplo de como, no mundo contemporâneo, ocorrências locais podem chegar a uma escala transnacional com velocidade avassaladora. Tais ocorrências exigem uma reação imediata e concertada dos protagonistas políticos internacionais - os Estados. Esse protagonismo, no entanto, está longe de ter o mesmo peso que tinha no auge da ordem internacional de Westfália, quando a comunidade internacional era composta por Estados formalmente iguais e soberanos. A evolução do Regulamento Sanitário Internacional e a criação, em 2005, da categoria Emergência de Saúde Pública de Importância Internacional (ESPII) - que lidou com casos da gripe A (H1N1) em 2009, da poliomielite e do Ebola e, atualmente, trata da associação entre o Zika e malformações congênitas - tem uma lógica moral subjacente: promover os bens comuns globais torna-se um problema em uma ordem internacional altamente fragmentada e ainda bastante dependente da soberania dos Estados (Krisch, 2010, p. 251).

Devemos tomar cuidado com uma analogia apressada entre problemas de saúde global e clima. As crises na área da saúde tendem a ter cadeias causais mais claras. Além disso, o diagnóstico e a avaliação do sucesso ou fracasso da maioria das medidas sanitárias coletivas, no plano nacional ou transnacional, desdobram-se, muitas vezes, de forma rápida. Na área climática, por sua vez, a relação entre causa e efeito não é tão visível em curto prazo. A própria noção de crise, que aqui é concebida como a eclosão de uma instabilidade sistêmica, que pode ser controlada pela adoção de medidas oportunas, não pode ser completamente aplicada aos problemas climáticos, pelo menos não na mesma escala 
temporal: a crise climática é mais duradoura, intergeracional. Tais características tornam o problema climático ainda mais explosivo.

No artigo "A tragédia dos comuns", Garret Hardin (1968) já previa os obstáculos que a cooperação internacional enfrentaria ao regular os bens comuns globais - que são os recursos que pertencem a todos, que podem ser usufruídos por cada um de nós livremente, como o ar que respiramos. Hardin oferece uma alegoria simples para explicar sua teoria. Ele imagina um pasto, que é aberto a qualquer pessoa para criar gado, como um bem comum. A tragédia ocorre quando cada criador percebe que é mais rentável adicionar a maior quantidade possível de gado ao pasto independentemente da perda coletiva que ele sofrerá ao longo do tempo. Assim, enquanto os lucros com a venda do gado serão auferidos pelo criador individualmente, as consequências negativas provenientes do esgotamento do bem comum serão compar236 tilhadas entre todos.

Essa metáfora fornece elementos para discutir o papel da propriedade privada no incentivo do comportamento econômico racional e o papel da autoridade política e do direito na coordenação de ações coletivas. Nas palavras do autor, a coordenação internacional é problemática porque:

[...] cada homem é preso a um sistema que o compele a aumentar seu rebanho sem limites - num mundo que é limitado. A ruína é o destino para o qual todos os homens correm, cada um perseguindo seu próprio interesse em uma sociedade que acredita na liberdade dos comuns. A liberdade de um bem comum traz ruína para todos (Hardin, 1968, p. 1244; tradução da autora).

O clima enfrenta um dilema coletivo similar. No entanto, a consequência de uma "pastagem excessiva" nesse recurso acarreta uma perda coletiva de outra magnitude. 
A classificação de um recurso como um bem comum global decorre de uma opção normativa ou de um dado fático ${ }^{4}$. Explicando melhor, tal classificação pode ser feita a partir de uma convicção moral de que alguns recursos ou questões políticas são de tal importância que devem ser protegidos globalmente ou como consequência das características de certos recursos que determinam uma ação coletiva concertada em escala global (Weiler, 2004, p. 556). Os direitos humanos são um exemplo da primeira categoria. A segunda categoria, por sua vez, comporta uma distinção mais refinada. Há problemas que não podem ser contidos por barreiras geográficas, como a disseminação de vírus e a poluição. Há outros problemas que, em tese, poderiam até ser resolvidos no âmbito doméstico dos Estados, mas tal fato não ocorre em razão do grau de interdependência em que vivemos (questões de comércio, segurança nacional e questões financeiras) ${ }^{5}$. Pode-se dizer, com certa razão, que essa divisão é frágil, pois o nível de interdependência (que caracteriza o segundo tipo) também impacta na escala e na velocidade de problemas ambientais e de saúde global (o primeiro tipo). Ainda assim, é importante defender uma distinção entre os dois tipos de problema: a falta de uma ação global concertada em questões como mudança climática e pandemias pode colocar em risco a própria existência humana, o que não ocorre com as questões relacionadas ao comércio internacional, as quais, em tese, poderiam ser reguladas por meio de uma integração mais sutil sem causar

4 Há uma extensa literatura sobre o assunto. Wijkman (1982, p. 511), por exemplo, explica que a ausência de direitos econômicos exclusivos e de uma estratégia de organização são fatores que levam à ineficiência econômica dos bens comuns. Esse autor define bem comum como "um recurso sobre o qual nenhuma unidade decisória tem direitos exclusivos” (p. 512).

5 Slaughter (2004, p. 16; tradução da autora) explica o conceito de governança global e interdependência: "A governança global não significa a regulação dos Estados da mesma forma como os Estados regulam seus cidadãos; a governança global significa abordar as questões e resolver os problemas que resultam do fato de os cidadãos tornarem-se globais." 
danos comparáveis. Tal distinção pode ser importante para demonstrar que problemas ambientais e de saúde global têm um grau maior de urgência que outros bens comuns globais, o que pode justificar experiências mais ousadas no âmbito das autoridades transnacionais.

A mudança climática nada mais é, portanto, do que uma das muitas ameaças globais que só pode ser razoavelmente resolvida de forma coletiva: qualquer resposta fornecida pelos Estados individualmente, ou por um grupo de Estados atuando de forma descoordenada, será, na melhor das hipóteses, limitada. Os efeitos globais de uma degradação ambiental não serão solucionados se o Estado "A" anunciar que vai reduzir sua quantidade de emissões e o Estado "B", que passa por um crescimento econômico, dobrar a quantidade de emissões. Barreiras políticas artificiais não impedem o aumento da concentração de gases de efeito estufa na atmosfera ${ }^{6}$.

238 Com relação ao meio ambiente, Alan Boyle (1993, p. 95) observa que a antiga noção de soberania "já não mais satisfaz as necessidades contemporâneas". No campo da mudança climática, bem como no da saúde global, a importância de uma autoridade internacional, independentemente de suas características institucionais, parece ser indiscutível. Tal autoridade tem a responsabilidade de evitar as decisões irracionais que tendem a ser adotadas por Estados atomizados, introspectivos e autointeressados. A soma das ações individuais racionais (se considerarmos "racional" como "autointeresse"), na ausência de regras que regulem todos

6 A afirmação de que o mundo não estaria melhor se os Estados, de forma unilateral, decidissem reduzir suas emissões pode ser defendida com base nos resultados de um estudo que calculou quanto a temperatura global poderia diminuir se um dos principais emissores (EUA, Índia ou China) reduzisse suas emissões em até $100 \%$ até 2200 . Os resultados são bastante modestos. Uma redução utópica de $100 \%$ das emissões dos EUA até 2200, por exemplo, resultaria em uma redução do aquecimento global de apenas 0,15 grau Celsius (Rogeberg, Andresen e Holtsmark, 2010, p. 184). 
os agentes envolvidos e coordenem as suas ações, é a irracionalidade coletiva ${ }^{7}$. Essa é a essência do dilema do prisioneiro (Dworkin, 2013, p. 27).

Criar uma coordenação internacional não é tarefa das mais simples. No domínio jurídico-político transnacional, como se sabe, não há um soberano com poder para decidir e implementar coercitivamente suas decisões. Apesar desse conhecido obstáculo das relações internacionais, os Estados não foram inertes.

O tipo de coordenação desenvolvido pela comunidade internacional para enfrentar a mudança climática é o tema da próxima seção. No entanto, a questão sobre se o atual regime é apropriado para enfrentar e solucionar tal ameaça permanece ainda sem resposta.

\section{Breve panorama do Regime Internacional de Mudança Climática}

A história do Regime Internacional de Mudança Climática pode ser dividida em três fases (Bodansky, 2010, p. 231). A primeira fase levou à adoção da Convenção Quadro, em 1992, que estabelece a base jurídica do regime, mas não cria qualquer mecanismo coercitivo para controlar as emissões de gases de efeito de estufa. A segunda fase é inaugurada com a adoção do Protocolo de Quioto, em 1997. O Protocolo de Quioto traça metas claras e obrigatórias, além de um prazo, de 2008 a 2012, para que os países desenvolvidos ("países do Anexo I") reduzam suas emissões. A última fase olha para o futuro do Regime, os passos após o fim do período de compromisso do Protocolo de Quioto. Tal fase culminou no Acordo de Paris, em 2015. A seguir, discutirei essas fases e apontarei os problemas que tradicionalmente impediram o progresso nas negociações climáticas.

7 Os bens globais, para Keohane e Victor (2010, p. 9), não são autorreguláveis, pois precisam de instituições formais que estabeleçam regras. 


\section{A mobilização em torno de dados científicos}

Inicialmente, a mudança climática surge como uma preocupação científica. No início dos anos 1960, cientistas descobriram um aumento das emissões antrópicas de gases que aprisionam o calor na atmosfera, como o dióxido de carbono, metano e óxido nitroso (Agrawala, 1998a, p. 606). A mudança climática somente transcende o meio científico e alcança o domínio político no momento em que um grupo de cientistas, associados à Organização Meteorológica Mundial (WMO, sigla em inglês), divulga sólidas evidências em torno da mudança climática e de suas consequências alarmantes, como o aquecimento incomum das temperaturas em todo o globo terrestre.

A criação do Painel Intergovernamental de Mudanças Climáticas (IPCC, sigla em inglês) em 1988, com o objetivo de avaliar os aspectos científicos da alteração climática, sinalizou a intenção dos Estados de interagir, finalmente, com a 240 comunidade científica e de lutar por uma ação concertada (Bodanski e Rajamani, 2015, p. 6). Em 1990, uma resolução da Assembleia Geral criou o Comitê de Negociações Intergovernamentais, através do qual os Estados deveriam negociar uma convenção sobre mudança climática.

\section{A Convenção Quadro sobre Mudanças Climáticas (Convenção Quadro)}

Em 1992, a Convenção Quadro foi adotada pela comunidade internacional. Convenções quadro possuem características específicas. De acordo com Bodansky (1993, p. 495), tais convenções têm um "papel catalisador" - elas preparam o terreno para que medidas mais incisivas possam ser aplicadas em um protocolo subsequente. As convenções constituem uma verdadeira técnica de direito internacional: Estados hesitantes tendem a aceitar mais facilmente regimes de governança genéricos, que não representam uma ameaça imediata à soberania. 
De acordo com tal abordagem, o objetivo da Convenção Quadro é fazer com que os 195 Estados-membros estabilizem suas concentrações de "gases de efeito estufa na atmosfera em um nível que impeça uma interferência antrópica perigosa no sistema climático" (art. 2). Por um lado, esse objetivo pode ser considerado ambicioso, já que a maioria dos Estados do mundo concorda em estabilizar a concentração de gases de efeito estufa na atmosfera (Skodvin e Andresen, 2011, pp. 170-71). Por outro, a mensagem torna-se fraca no momento em que a Convenção Quadro determina que a linha de segurança para tal concentração é impedir uma interferência antrópica "perigosa" no sistema climático. Decidir o que significa perigoso no contexto da alteração climática é uma tarefa complexa (Skodvin e Andresen, 2011, p. 171). Somente em 2009, os Estados concordaram, com base em evidências científicas, que uma interferência antrópica perigosa no sistema climático seria o aumento da temperatura global acima de 2 graus Celsius (Acordo de Copenhague, parágrafo 1).

A Convenção Quadro estabeleceu o princípio da "responsabilidade comum, mas diferenciada", segundo o qual todas as partes devem proteger o clima, mas os países desenvolvidos "devem assumir a liderança" nesta empreitada (art. 3.1). Tal princípio foi responsável por legitimar a divisão das obrigações impostas aos países desenvolvidos e aos países em desenvolvimento no âmbito do Regime Internacional de Mudança Climática (Skodvin e Andresen, 2011, p. 171).

A mudança climática, caracterizada pelo aumento dos níveis de concentração de gases de efeito estufa na atmosfera, é um produto direto da industrialização - um processo iniciado pelos países desenvolvidos. Como consequência desse fato, os países em desenvolvimento sempre consideraram justo atribuir aos países desenvolvidos a principal responsabilidade por adotar as medidas necessárias para evitar 
o aquecimento global ${ }^{8}$. Desse embate, restaram aos países desenvolvidos obrigações adicionais. Os países desenvolvidos devem, por exemplo, fornecer apoio técnico e financeiro para que os países em desenvolvimento cumpram suas obrigações (art. 4.3).

Mas a Convenção Quadro também traça obrigações comuns para os países desenvolvidos e para os países em desenvolvimento. Todos os Estados-membros devem produzir inventários nacionais de emissões antropogênicas e devem formular e implementar programas nacionais com o objetivo de combater o aquecimento global. Além disso, a Convenção Quadro incentiva a produção contínua do conhecimento científico sobre a mudança climática.

A Convenção Quadro representou o início do diálogo entre os Estados sobre o aquecimento global, mas havia ainda muita pressão para que os países desenvolvidos, principalmente, assumissem compromissos mais incisivos. Tal 242 pressão resultou na adoção do Protocolo de Quioto.

\section{O Protocolo de Quioto}

O Protocolo de Quioto foi assinado em 1997, mas entrou em vigor somente em 2005, após ratificação da Rússia (art. 25.1). Em uma linguagem mais assertiva, o Protocolo determina aos países desenvolvidos o dever de assegurar que suas emissões "não excedam as quantidades atribuídas [...] com o objetivo de reduzir suas emissões globais [...] em pelo menos $5 \%$ abaixo dos níveis de 1990 no período compreendido entre 2008 a 2012" (art. 3.1). Graças ao Protocolo de Quioto, portanto, cada país desenvolvido adquiriu uma "meta de redução ou limitação

\footnotetext{
8 Bodansky (1993, p. 479) esclarece este ponto ao dizer que os países em desenvolvimento consideram a mudança climática como uma questão "de desenvolvimento”, enquanto os países desenvolvidos colocam a mudança climática como um problema ambiental.
} 
de emissões"9, que deveria ser atingida no primeiro período de compromisso antes mencionado, ou seja, de 2008 a 2012.

O sucesso ao atribuir metas obrigatórias de "redução ou limitação de emissões" aos países desenvolvidos foi parcialmente frustrado em razão da ausência dos Estados Unidos no acordo final e da ausência de imposição de qualquer compromisso aos países emergentes considerados grandes emissores, como China, Índia e Brasil, para trilhar o caminho do desenvolvimento sustentável (Nordhaus, 2007, p. 33). Apesar dessas frestas, que prejudicam a efetividade do acordo, o Protocolo do Quioto criou mecanismos e procedimentos originais, que são hoje considerados referência para o direito internacional.

O primeiro exemplo da inovação institucional do Protocolo de Quioto foi a criação dos três mecanismos de mercado destinados a facilitar e a reduzir os custos envolvidos na implementação das obrigações dos países desenvolvidos. Eles são: a Implementação Conjunta, o Mecanismo de Desenvolvimento Limpo e o Comércio de Emissões. Em linhas gerais, tais mecanismos criam o comércio de créditos de redução de emissões. Tais créditos são gerados pela construção de infraestruturas sustentáveis nos países em desenvolvimento (Mecanismo de Desenvolvimento Limpo) ou nos países desenvolvidos (Implementação Conjunta). Os créditos de redução de emissões podem ser ainda comercializados entre países desenvolvidos (Comércio de Emissões). No final, estes países podem utilizar os créditos para cumprir suas metas de "redução ou limitação de emissões".

O segundo exemplo da criatividade institucional do Protocolo de Quioto foi adotar um sistema de cumprimento das

\footnotetext{
9 Baumert (2006, pp. 372-73) explica que a meta de cada país é diferente. Há países autorizados a aumentar suas emissões, acima dos níveis de 1990, e a Islândia é um deles, e os países obrigados a reduzir suas emissões, abaixo dos níveis de 1990, como a União Europeia.
} 
obrigações. Um Comitê de Cumprimento tem a competência para declarar que um país desenvolvido não cumpriu suas obrigações. Tal declaração deve respeitar o devido processo legal e deve ser adotada após análise técnica da situação.

Com a aproximação do fim do primeiro período de compromisso, era importante que os Estados passassem a negociar um acordo de longo prazo para regular o tema. Copenhague, local que sediaria a $15^{\mathrm{a}}$ Conferência das Partes, foi o palco escolhido para a decisão sobre o futuro do Regime Internacional de Mudança Climática.

\section{De Copenhague a Paris}

Copenhague não produziu aquilo que muitos tinham esperado $^{10}$. Aqueles que desejavam assinar um acordo legalmente vinculante, como a Convenção Quadro ou o Protocolo de Quioto, tiveram de se contentar com um instrumento essencialmente político e não consensual, o Acordo de Copenha244 gue. Em relações internacionais, acordos legalmente vinculantes representam o esforço máximo dos Estados soberanos para criar a coordenação de determinado objeto por meio do direito e das instituições. Os Estados reforçam os compromissos assumidos ao promoverem os necessários arranjos domésticos e internacionais para implementar e legitimar o acordo assinado ${ }^{11}$.

As negociações em Copenhague revelaram a extensão e a natureza das divergências sobre questões elementares.

\footnotetext{
${ }^{10}$ Para Dubash e Rajamani (2010, p. 593; tradução da autora): "Nunca uma negociação internacional atraiu 125 chefes de Estado e de governo e gastou tanto capital político e, ainda assim, fracassou, de forma tão espetacular, em atingir seus objetivos. E nunca os resultados dessa negociação foram tão desalinhados com as expectativas populares".

${ }^{11}$ Para Werksman (2010, p. 673; tradução da autora), acordos legalmente vinculantes ("legally binding agreement", LBA), são "a mais alta expressão da vontade política das partes em cumprir o acordo. Para muitos países, os 'acordos legalmente vinculantes' exigem ratificação parlamentar e, portanto, tornam-se vinculantes e aplicáveis no âmbito doméstico por meio da legislação de implementação".
} 
A primeira questão voltava-se para a arquitetura do futuro Regime Internacional de Mudança Climática, se deveria girar em torno de metas obrigatórias, impostas de "cima para baixo", como Quioto, ou em torno de metas voluntárias, estabelecidas de "baixo para cima" (Dubash e Rajamani, 2010, pp. 594-96). A segunda questão dizia respeito ao nível de obrigações a que países desenvolvidos e em desenvolvimento deveriam se submeter. Enquanto os países desenvolvidos clamavam por maior "simetria jurídica", os países em desenvolvimento queriam manter a "diferenciação legal" (Werksman, 2010, p. 672). Ao fim, o Acordo de Copenhague se distanciou do Protocolo de Quioto ao estabelecer metas voluntárias, estabelecidas de "baixo para cima". Ao mesmo tempo, determinou que tanto os países desenvolvidos quanto os países em desenvolvimento deveriam listar suas contribuições para redução das emissões de gases de efeito estufa. Pela primeira vez, portanto, as negociações incluíam as emissões dos países em desenvolvimento.

A $21^{\text {a }}$ Conferência das Partes em Paris, em dezembro de 2015, foi o evento mais recente e aguardado das negociações climáticas. Tal como noticiado pela mídia, essa seria a última oportunidade da comunidade internacional para decidir o futuro do Regime Internacional de Mudança Climática. A Conferência resultou na adoção do Acordo de Paris, avaliado como um sucesso por especialistas e representantes dos Estados.

É interessante notar que o Acordo de Paris consolida a arquitetura inicialmente construída em Copenhague: ele cristaliza o modelo em torno das metas voluntárias, as "contribuições nacionalmente determinadas", conforme o jargão técnico do Acordo, além de sinalizar para maior "simetria jurídica" entre os Estados-membros.

Em linhas gerais, o Acordo de Paris, cujo objetivo é manter o aumento da temperatura média mundial muito abaixo dos 2 graus Celsius, mas com a ambição de limitar 
tal aumento em 1,5 grau Celsius, aposta em algumas regras para se tornar, com o tempo, uma resposta mais eficaz ao aquecimento global.

Primeiro, há um dever em aumentar o nível de ambição das contribuições nacionalmente determinadas. Para o Acordo, as partes apresentarão, a cada cinco anos, novas contribuições nacionalmente determinadas, que devem representar um progresso em relação àquelas já indicadas (arts. 4.9 e 4.3 combinados).

Segundo, o Acordo coloca em operação mecanismos de accountability, ainda bastante incipientes, para verificar a implementação e a integridade das contribuições nacionalmente determinadas. Assim, informações sobre as contribuições nacionalmente determinadas devem demonstrar "clareza, transparência e entendimento" de regras específicas sobre o assunto (art. 4.8). Os relatórios contábeis das contribuições nacionalmente determinadas devem ter como base a 246 "integridade ambiental, transparência, exatidão, comparabilidade e consistência" (art. 4.13). O Acordo de Paris adotou um instrumento, denominado "global stocktake", que avaliará as ações adotadas pelos Estados para atingir os objetivos do Acordo. O resultado do "global stocktake" deverá nortear a atualização das contribuições nacionalmente determinadas, bem como toda a coordenação internacional na área (art. 14). Por fim, o Acordo cria um "mecanismo de transparência”, que ainda deverá ser formulado, para construir a confiança entre as partes e para permitir implementação efetiva dos termos do Acordo (art. 13).

Especialmente importante para a área de saúde global são os artigos que dispõem sobre a ajuda financeira e sobre a capacitação dos países em desenvolvimento, particularmente dos países mais vulneráveis, para implementar ações destinadas à mitigação e à adaptação aos efeitos do aquecimento global (art. 11). Políticas sanitárias deveriam fazer parte do pacote, o que será tratado na próxima seção. 


\section{Impactos da mudança climática sobre a saúde}

Quais são as consequências para a saúde caso as negociações climáticas fracassem? Ou melhor, o que ocorrerá se os Estados não atingirem o objetivo, estabelecido em Paris, de manter o aumento da temperatura global muito abaixo dos 2 graus Celsius? O Centro de Controle e Prevenção de Doenças (CDC, sigla em inglês), agência de proteção à saúde dos Estados Unidos, afirma que novas doenças surgirão e a gravidade de outras doenças existentes será acentuada (CDC, 2015).

Na Figura 1, o CDG ilustra com precisão os impactos da mudança climática na saúde. Da esquerda para a direita são apontados os efeitos diretos da alteração climática, os impactos causados ao meio ambiente e as consequências para a saúde das pessoas. Assim, é possível perceber que fenômenos meteorológicos mais severos causarão uma alteração na ecologia de potenciais vetores, o que afetará as doenças de transmissão vetorial como malária, dengue e chikungunya. Da mesma forma, o aumento de dióxido de carbono na atmosfera trará maior degradação ambiental, acarretando, consequentemente, incremento nas migrações forçadas, nos conflitos civis, e afetando a saúde mental das populações atingidas.

O que mais chama a atenção, no entanto, não são os dados apresentados, mas algo implícito no discurso sobre saúde e mudança climática. Como dito na introdução deste artigo, as populações que mais sofrerão as consequências da alteração climática são aquelas que menos contribuíram para o problema (as populações dos países em desenvolvimento), e, em razão do baixo desenvolvimento econômico da região onde vivem, são as populações com menor capacidade de se adaptar à nova realidade (Cf. Haines et al., 2006; Patz et al., 2007). Tal situação representa, possivelmente, "uma das maiores injustiças em matéria de saúde dos tempos atuais" (Patz et al., 2007, p. 397). 


\section{Figura 1}

\section{Impactos da mudança climática na saúde humana}

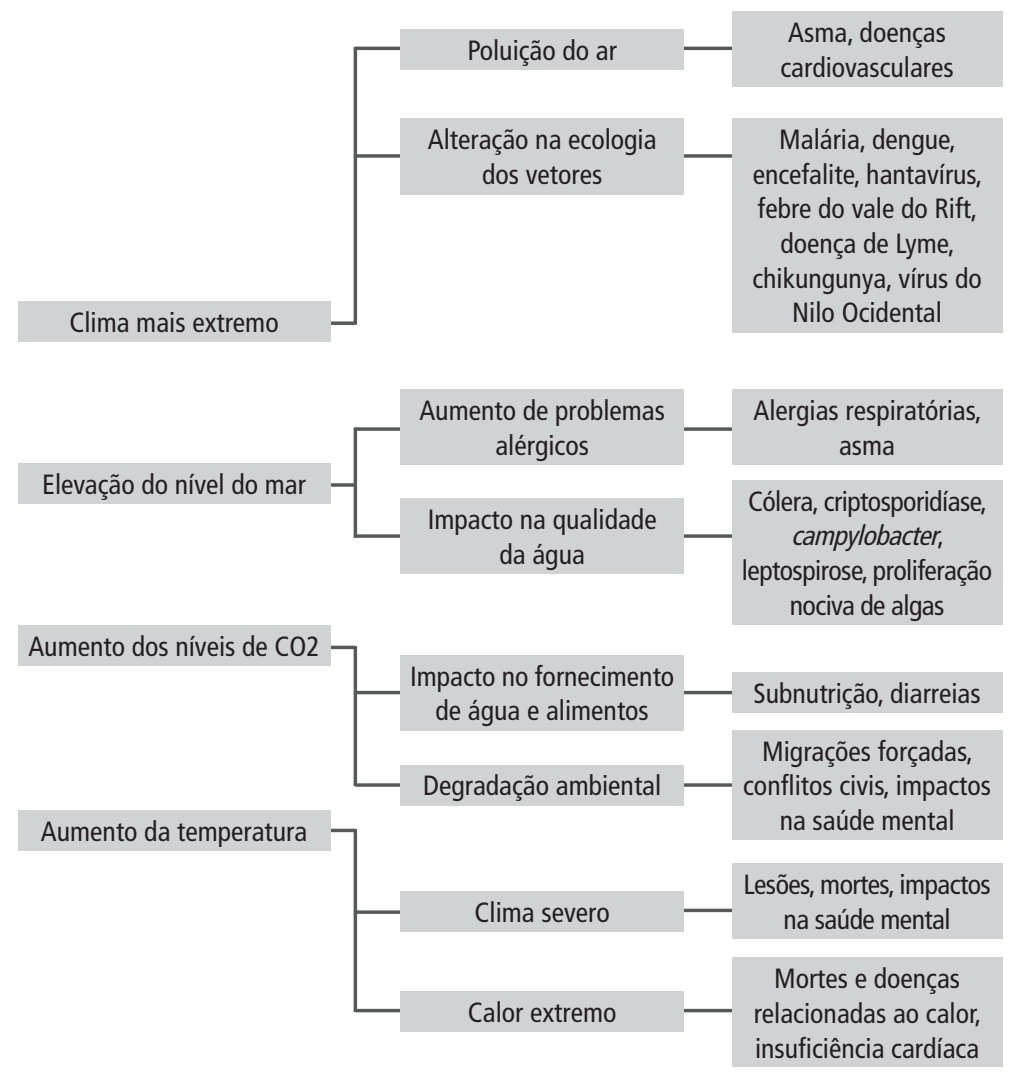

Fonte: Elaboração própria, com base em dados de CDC (2015).

Patz e colegas trazem o exemplo da malária para ilustrar a situação. Os autores relatam que fatores biológicos explicam por que a malária é altamente persistente na região da África Subsaariana - sua transmissão é mais propícia em áreas quentes e úmidas. Assim, essa região deve arcar não somente com os custos provenientes da doença 
propriamente dita, mas também com seus custos indiretos: maior abstenção de alunos e de trabalhadores, redução no turismo, ausência de investimento externo, entre outros. Não é à toa, dizem os autores, que a conclusão de alguns estudos aponta para a correlação perversa entre malária, pobreza e baixa taxa de crescimento econômico (Patz et al., 2007, pp. 400-401).

Os efeitos do aquecimento global, nesse contexto, somente reforçariam tal correlação e acabariam por perpetuar os sérios problemas sociais e econômicos enfrentados pela população da região. Na mesma linha, Haines e colegas (2006, p. 592) indicam que o maior impacto da alteração climática será concentrado em populações pobres, particularmente na parcela mais jovem dessas populações que já sofrem com as doenças mais sensíveis ao aquecimento global, como a malária.

Tais estudos demonstram que, no contexto da saúde, as discussões sobre mudança climática devem ir muito além da mitigação, que foca na redução das emissões de gases de efeito estufa. Apesar da mitigação ser essencial para resolver o problema, é a adaptação - medidas voltadas para proteger determinada população ou território dos efeitos adversos da alteração climática - que merece ser pauta obrigatória em qualquer estudo sobre o tema.

Uma comissão multidisciplinar, formada pela revista The Lancet, com o objetivo de mapear os impactos da mudança climática sobre a saúde e sugerir possíveis respostas, considera que o setor saúde tem um importante papel a cumprir "na liderança dos esforços de resiliência e adaptação aos efeitos da mudança climática" (The Lancet, 2015, p. 1874). Foram planos de adaptação que fizeram com que Bangladesh, por exemplo, reduzisse de forma expressiva o número de mortes que invariavelmente ocorrem após o país ser abatido por ciclones e inundações. Autoridades locais e organizações não governamentais conseguiram implantar melhores sistemas de alerta e 
construíram abrigos para as comunidades afetadas (The Lancet, 2015, p. 1875). Adaptação, portanto, não combate a mudança climática, mas diminui a vulnerabilidade das populações aos seus efeitos.

A Organização Mundial de Saúde (OMS) é um ator importante para alertar e preparar governos e comunidades para os riscos à saúde decorrentes da alteração climática. A OMS gerencia atualmente um Programa Global sobre mudança climática e saúde, o qual se apoia em quatro pilares: sensibilização sobre o problema; fortalecimento de parcerias; melhora das evidências científicas; e implementação das medidas da área da saúde. De acordo com o último pilar, a OMS utilizará sua capacidade técnica para ajudar os sistemas de saúde nacionais a se tornarem mais resilientes aos efeitos do aquecimento global (OMS, 2016).

\section{$* * *$}

A mudança climática é um dos problemas internacionais mais desafiadores do momento. Como vimos, as negociações intergovernamentais enfrentaram e ainda enfrentarão diversos obstáculos antes de chegar a um regime que efetivamente proteja o mundo de uma "interferência antrópica perigosa no sistema climático" (Convenção Quadro, art. 2).

Um desses obstáculos foi o aprofundamento do conflito entre países desenvolvidos e países em desenvolvimento. Os países em desenvolvimento, que já respondem pela maior parte das emissões do planeta (Baumert, Herzog e Pershin, 2005, p. 17), foram chamados a participar, de maneira mais ativa, do Regime Internacional de Mudança Climática.

As diferentes repercussões políticas geradas pelo tema também atrapalharam as negociações. $\mathrm{O}$ apoio popular, por exemplo, não foi sempre constante. De 2005 a 2008, a mudança climática ocupou o posto da "alta política", de acordo com Andresen e Skodvin (2011). A mudança climática era uma 
prioridade em diversas reuniões devido ao consenso científico cada vez mais claro sobre o problema. Os terríveis efeitos da mudança climática, como "tempestades tropicais, desaparecimento de geleiras, e imagens de ursos polares à procura por gelo", influenciavam populações a pleitear mais ações de seus governos. Essa trajetória ascendente, no entanto, foi revertida após a eclosão da crise econômica mundial em 2008 (Skodvin e Andresen, 2011, p. 165). Pesquisas mais recentes demonstram que a maioria dos cidadãos, em diversas regiões, apoia a limitação de emissões proposta pelo seu respectivo governo. Esse apoio é maior na América Latina e menor nos Estados Unidos e na China (Pew Research Center, 2015).

O Regime Internacional de Mudança Climática tem mais de vinte anos de história. Tal Regime está bem longe de resolver minimamente os problemas causados pela alteração climática. A arquitetura institucional desenhada em Paris ainda precisa ser estudada e avaliada com base em conceitos bem formulados e pressupostos normativos plausíveis. Se encararmos tal exercício como uma possível ferramenta de aperfeiçoamento institucional, adicionamos mais um elemento à equação que pode fazer com que os Estados cooperem de modo mais eficaz entre si para proteger o clima e, consequentemente, a saúde. Afinal, como conclui The Lancet (2015, p. 1861), "o combate à alteração climática seria a maior oportunidade para a saúde global do século 21 ”.

\section{Danielle Hanna Rached}

é pós-doutoranda do Instituto de Relações Internacionais da Universidade de São Paulo (IRI-USP); bolsista da Fundação de Amparo à Pesquisa do Estado de São Paulo (Fapesp).

\section{Bibliografia}

AGRAWALA, S. 1998a. Context and early origins of the intergovernmental panel on climate change. Climatic Change, n. 39, pp. 605-20. 
1998b. Structural and process history of the intergovernmental panel on climate change. Climatic Change, n. 39, pp. 621-42.

BAUMERT, K. A. 2006. Participation of developing countries in the International Climate Change Regime: lessons for the future. The George Washington International Law Review, n. 38, pp. 365-408.

BAUMERT, K. A; HERZOG, T.; PERSHIN J. 2005. Navigating the numbers: Greenhouse Gas Data and international climate policy. Washington: World Resources Institute.

BODANSKY, D. 1993. The United Nations Framework Convention on Climate Change: a commentary. Yale Journal of International Law, n. 18, pp. 451-558.

2010. The Copenhagen Climate Change Conference: a postmortem”. American Journal of International Law, n. 104, pp. 230-40. 2012. The Durban platform negotiations: goals and options.

Policy Brief, Harvard Project on Climate Agreements, Belfer Center for Science and International Affairs, Harvard Kennedy School, pp. 1-12. Disponível em: <http://belfercenter.ksg.harvard.edu/files/bodansky_durban2_ vp.pdf>. Acesso em: 3 jul. 2016. 2016. The legal character of the Paris Agreement. Review of European, Comparative, and International Environmental Law, [Forthcoming]. Disponível no SSRN: <http://ssrn.com/ abstract=2735252> ou <http: / dx.doi.org/10.2139/ssrn.2735252>. Acesso em: 3 jul. 2016.

BODANSKY, D.; RAJAMANI, L. 2015. The evolution and governance architecture of the climate change regime. In: SPRINZ, D.; LUTERBACHER, U. (eds.). International relations and global climate change: new perspectives [MIT Press, 2. edn., 2016. Forthcoming]. Disponível no SSRN: <ssrn.com/abstract=2168859>. Acesso em: 30 jun. 2016.

BOYLE, A. 1993. Environment and development: accountability through international law. Third World Legal Studies, n. 12, pp. 95-106.

CHAN, M. 2008. Message from WHO Director-General. Disponível em $<$ http:/ /www.who.int/world-health-day/dg_message/en/>. Acesso em: 15 abr. 2016.

DOBNER, P.; LOUGHLIN, M. (eds.). The twilight of constitutionalism?. New York: Oxford University Press.

DUBASH, N. K.; RAJAMANI, L. 2010. Beyond Copenhagen: next steps. Climate Policy, n. 10, pp. 593-99.

DWORKIN, R. 2013. A new philosophy for international law. Philosophy and Public Affairs, n. 41, pp. 2-30. 
HAINES, A. et al. 2006. Climate change and human health: impacts, vulnerability and public health. Public Health, n. 120, pp. 585-96.

HARDIN, G. 1968. The tragedy of the commons. Science, n. 162, pp. 1243-48. KEOHANE, R. 2015. Beyond the UNFCCC: rethinking the global politics of climate change. In: DOUGLAS, C. D. Lecture 2015 (Transcript). Disponível em: <https://www.chathamhouse.org/sites/files/ chathamhouse/field/field_document/20150511UNFCCCBobKeoha ne.pdf>. Acesso em: 3 jul. 2016.

KEOHANE, R.; VICTOR, D. 2010. The regime complex for climate change. Cambridge, Mass.: Harvard Kennedy School, The Harvard Project on International Climate Agreements (Discussion Paper 10-33).

KRISCH, N. 2010. Global administrative law and the constitutional ambition. In: DOBNER, P.; LOUGHLIN, M. The twilight of constitutionalism? Oxford Scholarship Online. Oxford University Press.

NORDHAUS, W. D. 2007. To tax or not to tax: alternative approaches to slowing global warming. Review of Environmental Economics and Policy, $\mathrm{n}$. 1, pp. 26-44.

PATZ, J. A. et al. 2007. Climate change and global health: quantifying a growing ethical crisis. EcoHealth, n. 4, pp. 397-405.

ROGEBERG, O.; ANDRESEN, S., HOLTSMARK, B. 2010. International climate treaties: the case for pessimism. Climate Law, n. 1, pp. 177-97.

SLAUGHTER, A. 2004. A new world order. New Jersey: Princeton University Press.

SKODVIN, T.; ANDRESEN, S. 2011. The climate regime: achievements and challenges. In: VIDAS, D.; SCHEI, P. J. (eds.). The world ocean in globalisation. Leiden, Boston: Martinus Nijhoff Publishers/Brill.

WEILER, J. H. H. 2004. The geology of international law - governance, democracy and legitimacy. ZaoRV, n. 64, pp. 547-62.

WERKSMAN, J. 2010. Legal symmetry and legal differentiation under a future deal on climate. Climate Policy, 10, pp. 672-77.

WIJKMAN, M. 1982. Managing the global commons. International Organization, n. 36, pp. 511-36.

\section{Documentos}

ACORDO de Copenhague. 2010 (30 mar.). Decisão 2/CP.15FCCC/ CP/2009/11/Add.1.

ACORDO de Paris. 2016 (29 jan.). Decisão 1/CP.21.FCCC/CP/2015/10/Add.1. CONVENÇÃO Quadro sobre Mudança Climática. 1992 (9 maio).

Disponível em: <http://unfccc.int/resource/docs/convkp/conveng. pdf $>$. Acesso em: 3 jul. 2016. 
PROTOCOLO de Quioto. 1997 (11 dez.). Disponível em: <http://unfccc. int/resource/docs/convkp/kpeng.pdf>. Acesso em: 3 jul. 2016.

\section{Relatórios e comissões}

CDC - Centers for Disease Control and Prevention. 2015. Climate effects of health. Disponível em: <http://www.cdc.gov/climateandhealth/ effects/>. Acesso em: 3 jul. 2016.

OMS - Organização Mundial de Saúde. 2016. WHO Global Programme on Climate Change $\mathcal{E}^{\circ}$ Health. Disponível em: <http:/ /www.who.int/ globalchange/mediacentre/news/WHO-Climate-change-ProgrammeSummary-2016-2017.pdf?ua=1>. Acesso em: 3 jul. 2016.

PEW RESEARCH CENTER. 2015. Global concern about climate change, broad support for limiting emissions. Disponível em: <http://www.pewglobal. org/2015/11/05/global-concern-about-climate-change-broad-supportfor-limiting-emissions/>. Acesso em: 3 jul. 2016.

THE LANCET. 2015. Health and climate change: policy responses to protect public health. The Lancet, n. 386, pp. 1861-914.

WORLD BANK. 2012. Turn down the heat: why a $4^{\circ} \mathrm{C}$ warmer world must be avoided?. A Report for the World Bank by the Potsdam Institute for Climate Impact Research and Climate Analytics, Washington, DC. 


\section{INTERFACES ENTRE $O$ REGIME INTERNACIONAL DE MUDANÇA CLIMÁTICA E A SAÚDE GLOBAL}

\section{DANIELLE HANNA RACHED}

Resumo: Apesar de saúde global e mudança climática serem fenômenos complexos e imbricados, eles ainda pertencem a mundos diversos. Com o objetivo de identificar interfaces entre os dois campos, o presente artigo analisa a evolução do Regime Internacional de Mudança Climática: suas características, obstáculos e principais decisões.

Palavras-chave: Regime Internacional de Mudança Climática; Saúde Global, bem comum global, mitigação e adaptação.

\section{INTERFACES BETWEEN THE INTERNATIONAL REGIME ON CLIMATE CHANGE AND GLOBAL HEALTH}

Abstract: Although climate change and global health are complex and intertwined phenomena, they still belong to different worlds. In order to identify interfaces between the two fields, this paper analyses the evolution of the International Regime on Climate Change: its features, obstacles, and key decisions.

Keywords: International Regime on Climate Change; Global Health, global common good, mitigation, and adaptation.

Recebido em: 26/5/2016

Aprovado em: 17/6/2016 